\title{
Outcome of Critically Ill Subjects With Tuberculosis: Systematic Review and Meta-Analysis
}

\author{
Valliappan Muthu MD DM, Ritesh Agarwal MD DM, Sahajal Dhooria MD DM, \\ Ashutosh N Aggarwal MD DM, Digambar Behera MD, and Inderpaul Singh Sehgal MD DM
}

\begin{abstract}
BACKGROUND: The outcomes of patients with tuberculosis admitted to an ICU remain undetermined. Herein, we reviewed the literature to describe the mortality of subjects with tuberculosis who are critically ill, and explore the effect of glucocorticoids on survival. METHODS: A systematic review of medical literature databases was performed for studies that describe the outcome of subjects with tuberculosis who required ICU admission. We calculated the proportion of hospitalized subjects with tuberculosis who required ICU admission. Pooled estimates of ICU and hospital mortality, and tuberculosis-related ARDS were calculated. We also studied the effect of systemic glucocorticoids on survival of subjects with tuberculosis who were critically ill. RESULTS: A total of 35 studies $(N=1,815)$ were included. The pooled proportion of hospitalized subjects with tuberculosis who required ICU admission was 3.4\% (95\% CI 1.6-5.7\%). The pooled ICU and hospital mortality was $48 \%$ (95\% CI $41-55 \%)$ and $54 \%$ (95\% CI 46-62\%), respectively. Tuberculosis-related ARDS was associated with higher odds (odds ratio 3.88, 95\% CI 1.73-8.72) of death. The use of glucocorticoids was not related to an improvement in survival (odds ratio $0.65,95 \%$ CI 0.27-1.57). CONCLUSIONS: Tuberculosis is a rare cause of ICU admission but is associated with high mortality. Tuberculosis-related ARDS is also associated with lower survival. The role of glucocorticoids in patients with tuberculosis who are critically ill remains unclear and needs further evaluation. Key words: tuberculosis; intensive care; acute lung injury; acute respiratory distress syndrome; steroids. [Respir Care 2018;63(12):1541-1554. (c) 2018 Daedalus Enterprises]
\end{abstract}

\section{Introduction}

Tuberculosis is an important cause of morbidity and mortality globally. Occasionally, patients with tuberculosis may present acutely and require intensive care, especially those with rapid symptom onset. ${ }^{1-4}$ Despite decades

Drs Muthu, Agarwal, Dhooria, Aggarwal, Behera, and Sehgal are affiliated with Department of Pulmonary Medicine, Postgraduate Institute of Medical Education and Research, Chandigarh, India.

The authors have disclosed no conflicts of interest.

Supplementary material related to this paper is available at http:// www.rcjournal.com.

Correspondence: Inderpaul Singh Sehgal MD, DM, Department of Pulmonary Medicine, Postgraduate Institute of Medical Education and Research, sector 12, Chandigarh, India 160012. E-mail: inderpgi@outlook.com.

DOI: $10.4187 /$ respcare .06190 of research, many facets of tuberculosis in patients who are critically ill remain unclear. For instance, the proportion of individuals with tuberculosis who require admission to an ICU has been variably reported, ranging from $<1 \%$ to $>8 \%$. 5,6 Even in countries with a high tuberculosis burden, the proportion of patients with tuberculosis who require ICU admission is different across centers. ${ }^{6,7}$ Similarly, the survival and the factors responsible for mortality among patients with tuberculosis who are critically ill are uncertain, despite the availability of effective antituberculosis therapy and improvement in the standards of ICU care. 6,7

In some but not all studies, the presence of ARDS and miliary tuberculosis has been shown to be associated with high mortality. ${ }^{5-9}$ Systemic glucocorticoids are often used in patients with tuberculosis who are critically ill, with an aim to improve survival. In fact, in a recent meta-analysis, the use of systemic glucocorticoids was shown to improve survival. ${ }^{10}$ However, this study did not specifically report the outcomes in subjects with tuberculosis who were crit- 


\section{TUBerCULOSIS IN THE ICU}

ically ill. Thus, the role of systemic glucocorticoids in the those who are critically ill still remains speculative., ${ }^{1,5}$ The current review was performed to ascertain mortality in subjects with tuberculosis who were critically ill and who required ICU care. We also investigated whether the use of systemic glucocorticoids improves survival in subjects with tuberculosis who were critically ill.

\section{Methods}

This review was reported in accordance with the guidelines of PRISMA (Preferred Reporting Items for Systematic Reviews and Meta-Analyses) statement. ${ }^{11}$ Ethics committee approval was not required because this was a systematic review of published data.

\section{Search Strategy}

We searched the PubMed, Embase, and Scopus databases from inception until May 1, 2017, for studies that describe outcomes of subjects with tuberculosis who required ICU admission. We used the following free-text terms: ("tuberculosis" or "TB" or "Mycobacterium tuberculosis" or "MTB" or "pulmonary TB" or "extrapulmonary TB") and ("critical care" or "intensive care unit" or "ICU" or "respiratory failure" or "ARDS" or "acute lung injury" or "acute respiratory distress syndrome" or "adult respiratory distress syndrome" or "ALI" or "ARF" or "acute hypoxic respiratory failure" or "hypoxic respiratory failure"). The reference lists of all the included articles and previous review articles were reviewed to search for additional studies.

\section{Inclusion Criteria}

We included studies that describe the course of subjects with active tuberculosis who required ICU admission. The following were excluded: (a) case series with $<10$ subjects, case reports, correspondence, letters, editorials, conference abstracts, and reviews; (b) studies that did not provide information about outcomes; (c) studies published in non-English language; (d) animal studies; (e) studies that primarily included subjects with tubercular meningitis or sequelae of tuberculosis in the past; and, (f) studies conducted outside the ICU setting.

\section{Initial Review of Studies}

A database was created from the electronic searches by using the reference manager Endnote (version X8, Clarivate Analytics, Philadelphia, Pennsylvania), and duplicate citations were discarded. Two authors (VM, ISS) screened these citations and identified the relevant studies from the title and abstract. Any disagreement was resolved by dis- cussion between these two authors. After scrutinizing the database to include only primary articles, the full texts of these studies were obtained and reviewed in detail.

\section{Study Selection and Data Abstraction}

All the studies were independently assessed by 2 authors (VM, ISS) for inclusion in the systematic review. Data were then extracted and entered into a standard data abstraction form. The following information was recorded: (i) details of publication (authors, country, and year of publication); (ii) study design (prospective or retrospective); (iii) criteria used for making a diagnosis of tuberculosis; (iv) number of subjects (including the demographic profile) and the inclusion criteria; (v) presence of comorbid illness(es); (vi) proportion of subjects with drug-resistant tuberculosis and past history of tuberculosis; (vii) details and duration of mechanical ventilation, length of hospital and ICU stay; (viii) treatment regimen used; (ix) use of glucocorticoids; (x) factors predicting mortality; and (xi) the final outcome.

\section{Assessment of Study Quality}

Two authors (VM, ISS) independently assessed the quality of the included studies by using the QualSyst tool. The QualSyst tool includes a set of 10 questions, with each question having a possible score of 0,1 , or $2 .{ }^{12}$ Interobserver agreement for the selection of studies was assessed by using the weighted Cohen's kappa.

\section{Data Analysis}

The statistical software packages RevMan (Review Manager, version 5.3, 2014, The Nordic Cochrane Centre, The Cochrane Collaboration, Copenhagen, Denmark) and StatsDirect (version 3, StatsDirect, Cambridge, United Kingdom) were used to perform the statistical analyses.

\section{Determination of the Pooled Effect}

For each study, we calculated the proportion with $95 \%$ CI of hospitalized subjects with tuberculosis who required ICU admission, and the proportion of subjects with tuberculosis in an ICU. We calculated the ICU and hospital mortality among subjects with tuberculosis admitted to the ICU for the individual studies. Forest plots were constructed to display the pooled results by using the random effects model.

\section{Sensitivity Analysis}

Sensitivity analysis was planned to estimate the crude odds ratio with $95 \% \mathrm{CI}$ of mortality in tuberculosis-related 


\section{TUBERCULOSIS IN THE ICU}

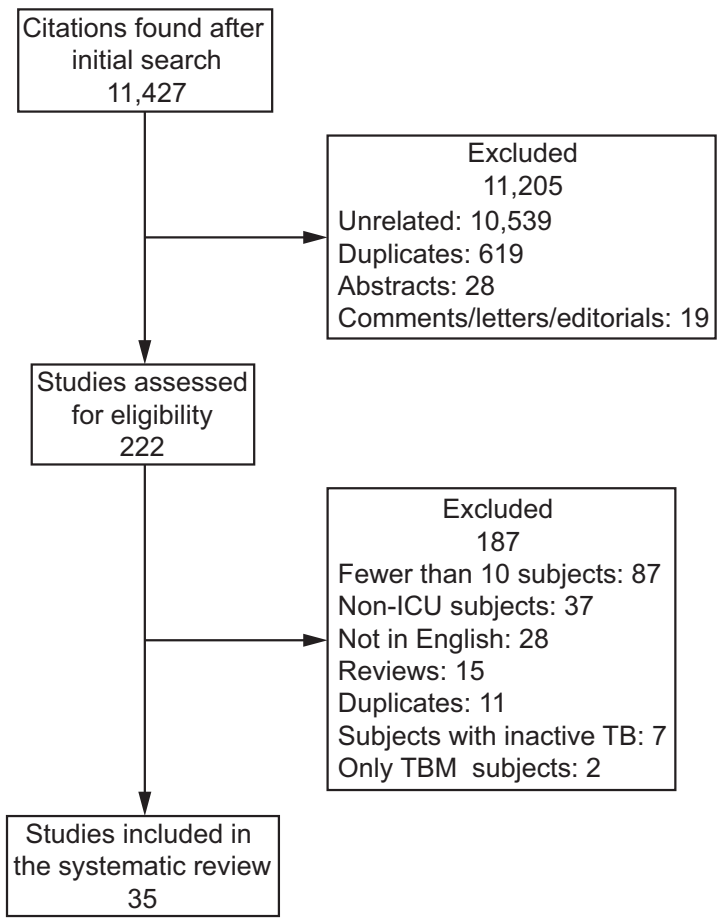

Fig. 1. Flow chart. $T B=$ tuberculosis; $T B M=$ tuberculosis meningitis.

ARDS and miliary tuberculosis. The mortality in subjects with tuberculosis who were critically ill and treated with glucocorticoids was also analyzed.

\section{Assessment of Heterogeneity}

Heterogeneity for the individual outcomes was assessed by using the $\mathrm{I}^{2}$ test, with a value of $\geq 50 \%$, which indicated significant heterogeneity. ${ }^{13}$

\section{Estimation of Publication Bias}

The presence of publication bias was evaluated by using the funnel plot (log proportion on the horizontal axis against standard error of proportion on the vertical axis). Publication bias was also assessed by using the Egger test ${ }^{14}$ and the Begg-Mazumdar test. ${ }^{15}$

\section{Results}

The initial database search yielded 11,427 citations, of which 35 studies $(N=1,815)$ were included in the current analysis (Fig. 1). ${ }^{1-3,5-7,16-44}$ All the studies except $\mathrm{two}^{3,35}$ had a retrospective study design. Of the included studies, 19 studies were from high tuberculosis burden countries. ${ }^{2,3,5-7,18,19,22-24,26-28,31,35,37,39,42,43}$ One study each exclusively included subjects who were critically ill with chronic kidney disease ${ }^{29}$ or with human immunodeficiency virus ${ }^{42}$ and affected with tuberculosis. Six studies included only subjects with tuberculosis-related ARDS. ${ }^{5-7,23,31,41}$ The most common indication for ICU admission was acute respiratory failure (mean $64.1 \%, 95 \% \mathrm{CI}$ $53.5-74.7 \%$ ) (Table 1). The common causes of acute respiratory failure were pneumonia and ARDS (with or without miliary tuberculosis). ${ }^{25,33}$

The other indications for ICU admission included sepsis (with or without shock), neurologic dysfunction, hemoptysis, and multiorgan failure (Table 1). The proportion of subjects with a prior history of tuberculosis (6 studies) ranged from 3 to $50 \%$, whereas the proportion of subjects with multidrug-resistant tuberculosis (17 studies) ranged from 0 to $17 \%$. The proportion of subjects who required mechanical ventilation was between 37.9 and $100 \%$ (Table 2). Invasive mechanical ventilation was the most common form of ventilation. The duration of mechanical ventilation was between 3 and $40 \mathrm{~d}$. The ICU length of stay (5-28 d) and the hospital length of stay (13-87 d) was also variable.

Nosocomial pneumonia, ventilator-associated pneumonia, urinary tract infection, and bacteremia were the common hospital-acquired complications. Pneumothorax due to mechanical ventilation was reported between 4 to $17 \%$ of the subjects (Table 2). The major factors that contributed to an ICU or hospital mortality included the presence of multiorgan failure, sepsis, development of nosocomial infections, cardiogenic shock, and refractory hypoxemia (see Supplemental Table 1 at http://www.rcjournal.com). One study described predictors of developing ARDS in subjects with tuberculosis who were critically ill. ${ }^{6}$ These included miliary tuberculosis, shorter duration of illness $(<30 \mathrm{~d})$, lymphopenia $\left(<1,625 \mathrm{cells} / \mathrm{mm}^{3}\right)$ and elevated serum alanine aminotransferase $(>100 \mathrm{IU}){ }^{6}$

Fifteen studies described the use of systemic glucocorticoids (see Supplemental Table 2 at http://www.rcjournal. com). ${ }^{1,5,6,18,21,23-25,27,28,31,40,41,43,44}$ The common indications for the use of glucocorticoids were miliary tuberculosis, respiratory failure, ARDS, and shock. Eight studies compared mortality in subjects with and without glucocorticoids (Supplemental Table 2). 1,5,24,27,28,40,43,44 Only one study provided the details of dose and duration of glucocorticoids (methylprednisolone, $80 \mathrm{mg} / \mathrm{d}$ for $5 \mathrm{~d}$ ) used. ${ }^{5}$

\section{Quality of Studies}

Most of the included studies were of poor quality, with a median (interquartile range) QualSyst score of 11 (1013) (see Supplemental Table 3 at http://www.rcjournal. com). The interobserver agreement for scoring the study quality was good (weighted Cohen's kappa $=0.92$ ). 


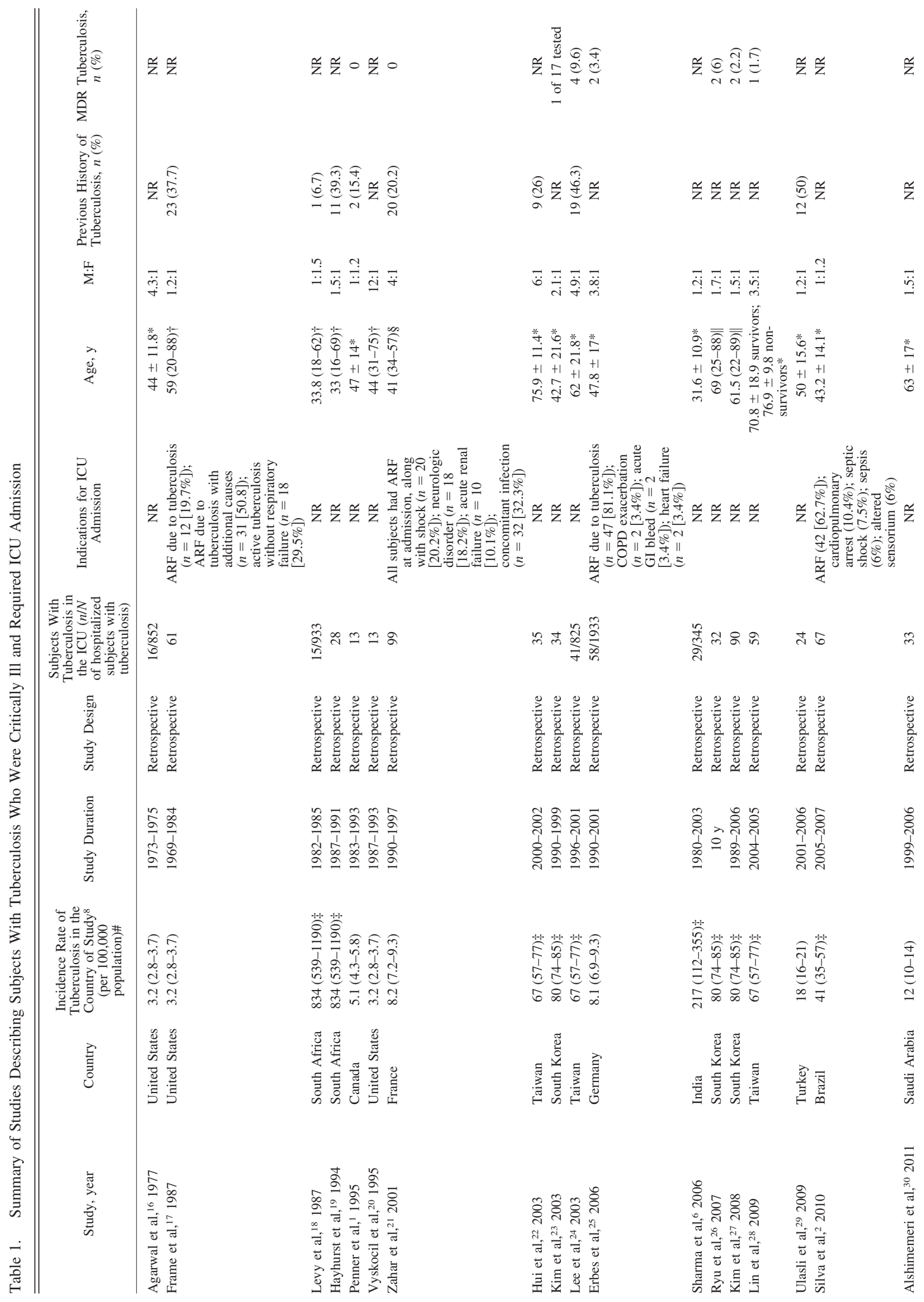




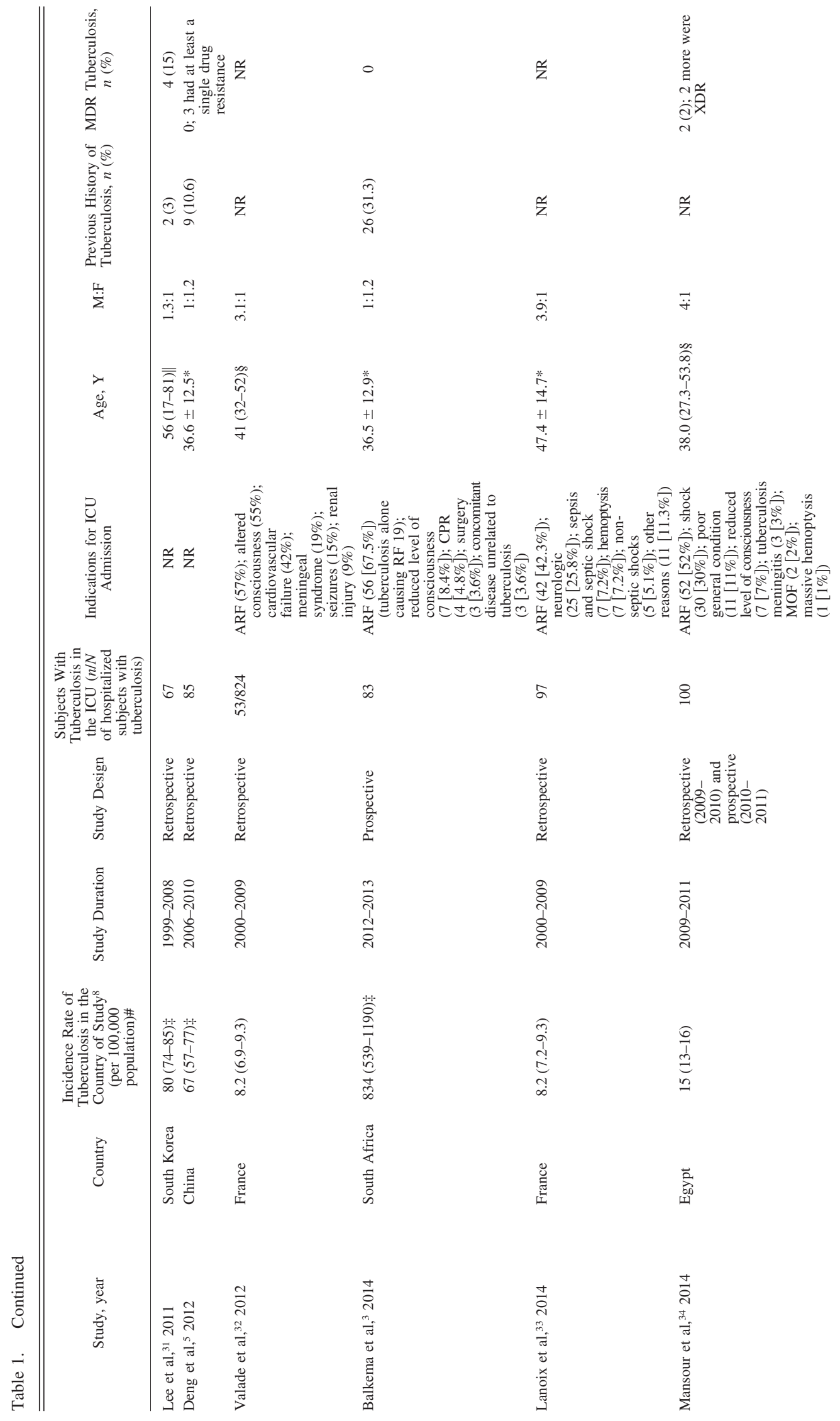




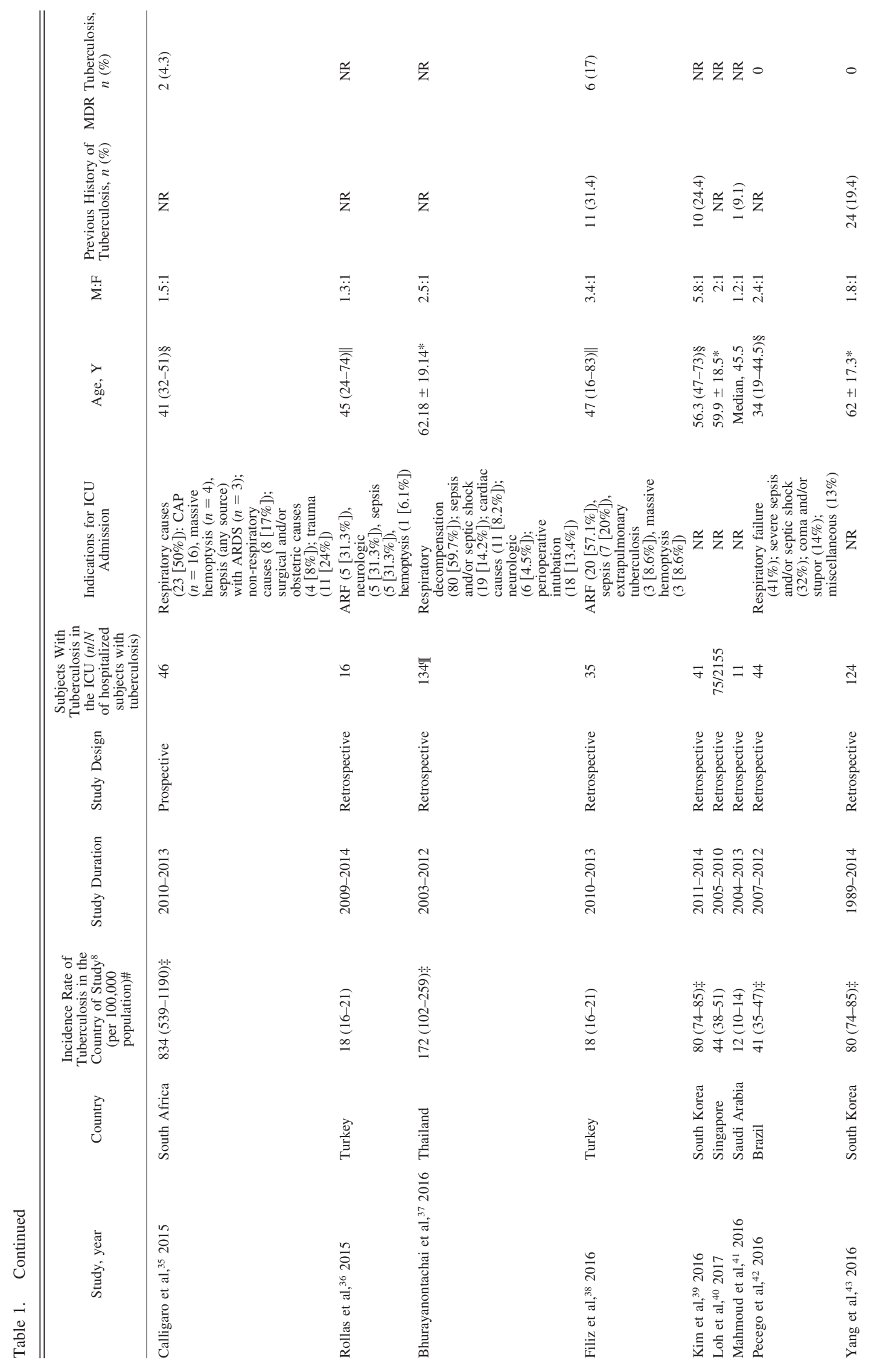


TUBERCULOSIS IN THE ICU

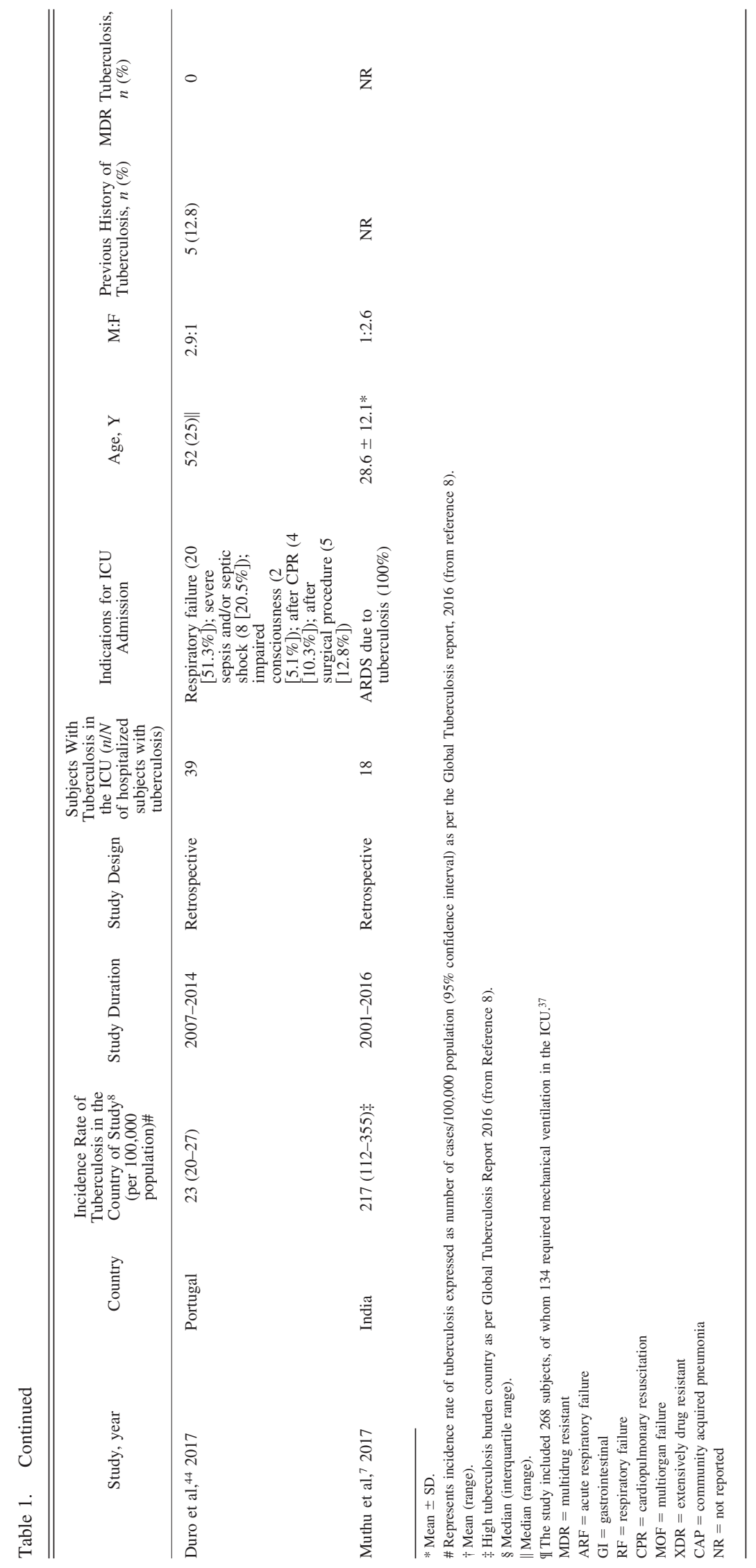




\section{TUBerCULOSIS IN THE ICU}

\section{Pooled Proportion of Subjects With Tuberculosis Who Were Critically Ill}

The proportion of all hospitalized subjects with tuberculosis who required ICU admission was between $0.5 \%$ and $8.4 \%$, with a pooled proportion of $3.4 \%(95 \% \mathrm{CI}$ $1.6-5.7, \mathrm{I}^{2}=96.6 \%, P<.001$ ) (see Supplemental Fig. 1 at http://www.rcjournal.com). ${ }^{5,6,16,18,24,25,32,40}$ The pooled proportion of all subjects with tuberculosis as an indication for ICU admission was 2.3\% (95\% CI 1.1-4, $\left.\mathrm{I}^{2}=95.5 \%, P<.001\right)^{7,17,19,22,28,35}$

\section{Pooled Effect}

The mortality of subjects with tuberculosis who are critically ill varied from 17 to $67 \%$. $^{1-3,5-7,16-44}$ The pooled ICU (26 studies $[n=1,282])^{2,3,5-7,18,19,23-26,38,40-42,44}$ and hospital mortality ( 23 studies $[n=1,283])^{1,3,16,17,20-26,28,31,33,36-40,42-44}$ was $48 \%\left(95 \%\right.$ CI $\left.41-55 \%, \mathrm{I}^{2}=86.11 \%, P<.001\right)$ and $54 \%$ (95\% CI $\left.46-62 \%, \mathrm{I}^{2}=92.58 \%, P<.001\right)$, respectively (Fig. 2).

\section{Sensitivity Analysis}

The pooled mortality in subjects with miliary tuberculosis (20 studies $[n=354])^{1-3,5-7,18,23-25,27-29,31,32,34,36,40,41,43}$ and tuberculosis-related ARDS (18 studies $[n=$ 486]) $)^{1-3,5-7,18,21,23-25,27,31,33,40,41,43,44}$ was $50 \%$ (95\% CI 43$\left.57 \%, \mathrm{I}^{2}=43.6 \%, P=.02\right)$ and $57 \%(95 \%$ CI $51-63 \%$, $\mathrm{I}^{2}=53.3 \%, P=.004$ ), respectively (Fig. 2). Tuberculosisrelated ARDS ( 9 studies, $n=587$ ) 2,3,23-25,27,33,40,44 was found to be associated with higher odds of death compared with non-ARDS tuberculosis (pooled odds ratio 3.88, 95\% CI 1.73$8.72, \mathrm{I}^{2}=68 \%, P=.02$ ) (Fig. 3). The presence of miliary tuberculosis (16 studies, $n=776$ ) 2,3,6,7,18,23-25,27-29,32,34,36,40,41 did not increase the risk of death vis-a-vis non-miliary tuberculosis (pooled odds ratio $1.15,95 \% \mathrm{CI} 0.71-1.87, \mathrm{I}^{2}=74 \%$, $P=.24$ ) (Fig. 3). The use of systemic glucocorticoids (8 studies, $n=526)^{1,5,24,27,28,40,43,44}$ did not improve survival in subjects with tuberculosis who were critically ill (odds ratio 0.65 , $95 \%$ CI $0.27-1.57, \mathrm{I}^{2}=76$ ) (Fig. 4). One study described the use of glucocorticoids exclusively in subjects with tuberculosis-related ARDS and found a reduction in mortality. ${ }^{5}$

\section{Heterogeneity}

There was significant heterogeneity in the included studies. The $\mathrm{I}^{2}$ value was $86.1 \%$ and $92.6 \%$ for studies that describe the ICU and hospital mortality, respectively.

\section{Publication Bias}

Publication bias was assessed for studies by estimating the proportion of subjects with tuberculosis in the ICU, proportion of hospitalized subjects with tuberculosis who required ICU and studies reported ICU and hospital mortalities. There was publication bias on visual inspection of the funnel plot (see the Supplemental Fig. 2 at http:// www.rcjournal.com); however, there was no evidence of publication bias on the Egger test ${ }^{14}(P=.92, P=.66$, $P=.37$, and $P=.67$ for hospital mortality, ICU mortality, mortality due to miliary tuberculosis, and ARDS, respectively) and the Begg-Mazumdar test ${ }^{15}(P=.71, P=.97$, $P=.61$, and $P=.92$ for hospital mortality, ICU mortality, mortality due to miliary tuberculosis, and ARDS, respectively).

\section{Discussion}

The results of this meta-analysis indicated that tuberculosis is an uncommon indication for ICU admission (3.4\% of hospitalized subjects with tuberculosis and $2.3 \%$ of all ICU admissions). The overall mortality of subjects with tuberculosis who were critically ill was high (48\% and $54 \%$, ICU and hospital mortality, respectively), with tuberculosis-related ARDS having higher odds of death compared with those without ARDS. The use of systemic glucocorticoids did not improve survival in subjects with tuberculosis who were critically ill.

Tuberculosis remains an uncommon indication for ICU admission. Early detection, availability of effective antituberculosis therapy, and assurance of high adherence to anti-tuberculosis therapy under directly observed therapy could explain the lower prevalence of tuberculosis in the ICU. However, it might also be possible that patients with tuberculosis who are critically ill are not admitted to the ICU due to the lack of infection control measures, such as negative pressure rooms, requisite air exchanges, and high efficiency particulate air filtration, especially in resourceconstrained settings. ${ }^{45}$

Once admitted to the ICU, there is high mortality in individuals with tuberculosis who are critically ill, and this has been attributed to several factors. These include the presence of comorbid illness, delay in initiating anti-tuberculosis therapy, unpredictable pharmacokinetics, and pharmacodynamics of anti-tuberculosis therapy in the patient who is critically ill, disseminated tuberculosis, ARDS, drug-resistant tuberculosis, delay in identifying patients with tuberculosis at a higher risk of mortality, and the lack of use of objective criteria for risk stratification. ${ }^{1,4,32}$ The high mortality could also reflect a referral bias with the sickest of patients getting admitted to ICU. ${ }^{37}$ Finally, infection with Mycobacterium tuberculosis may suppress monocyte expression that causes a state of immunosuppression that could possibly increase the risk for secondary 


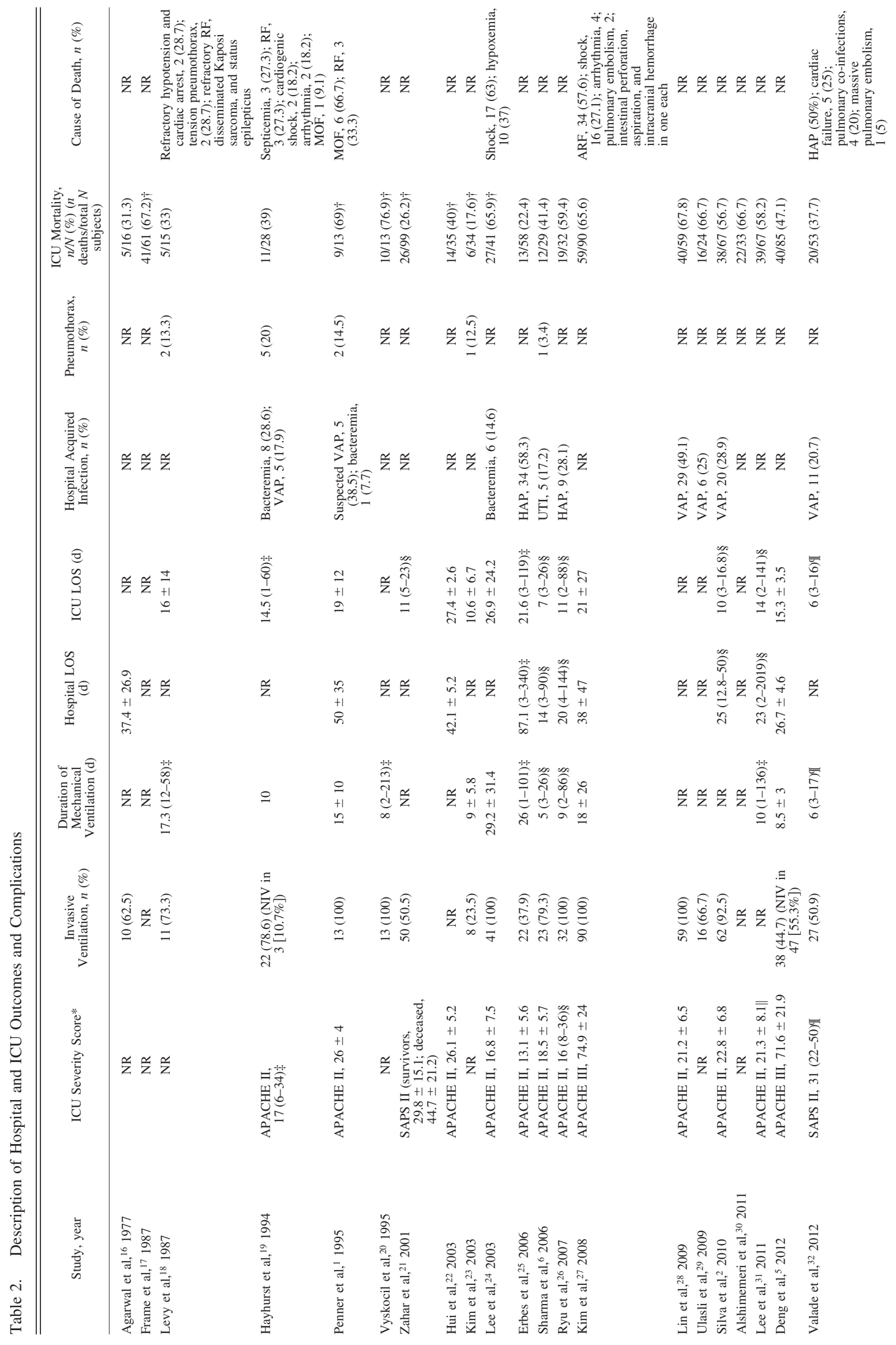




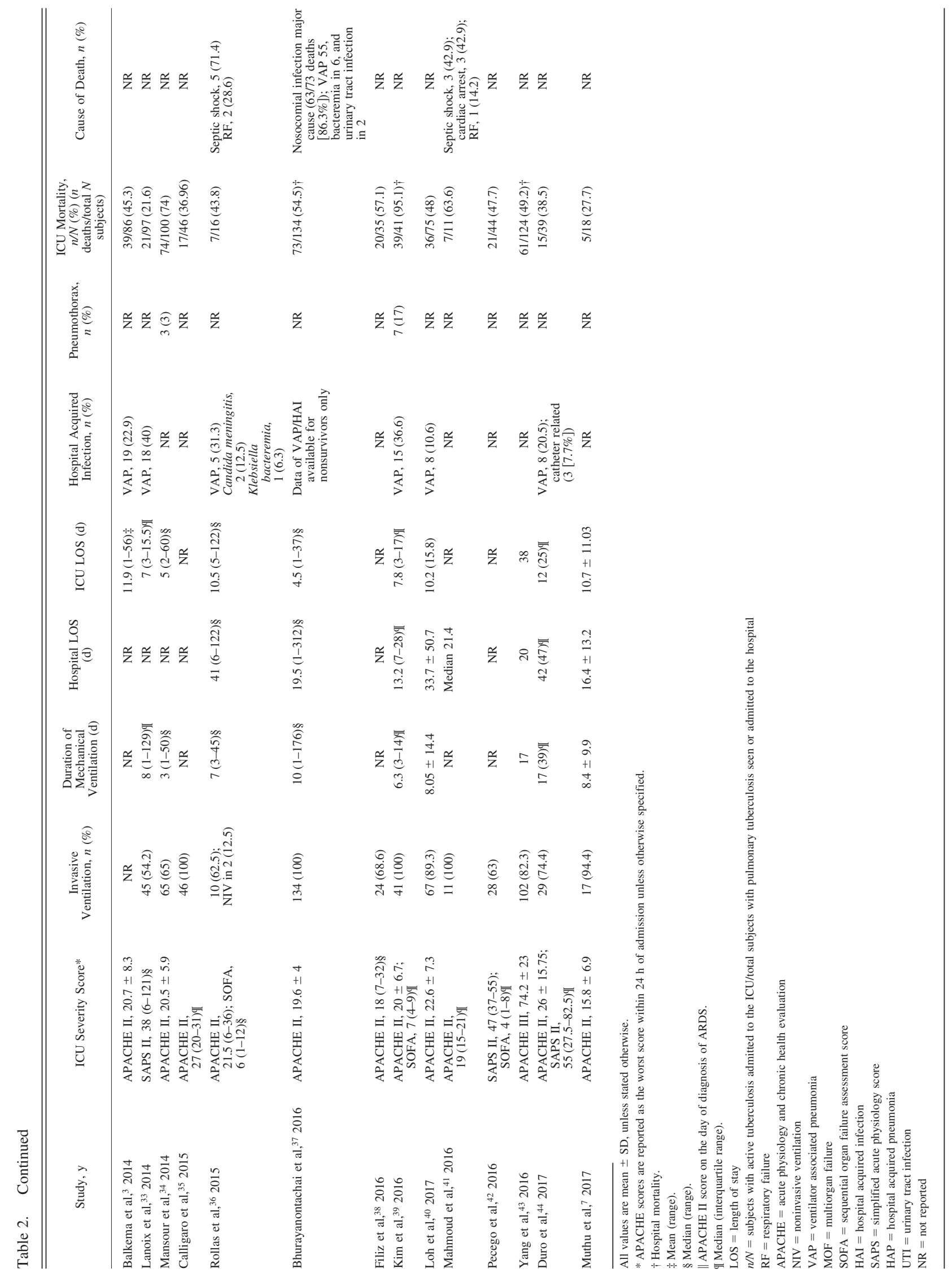



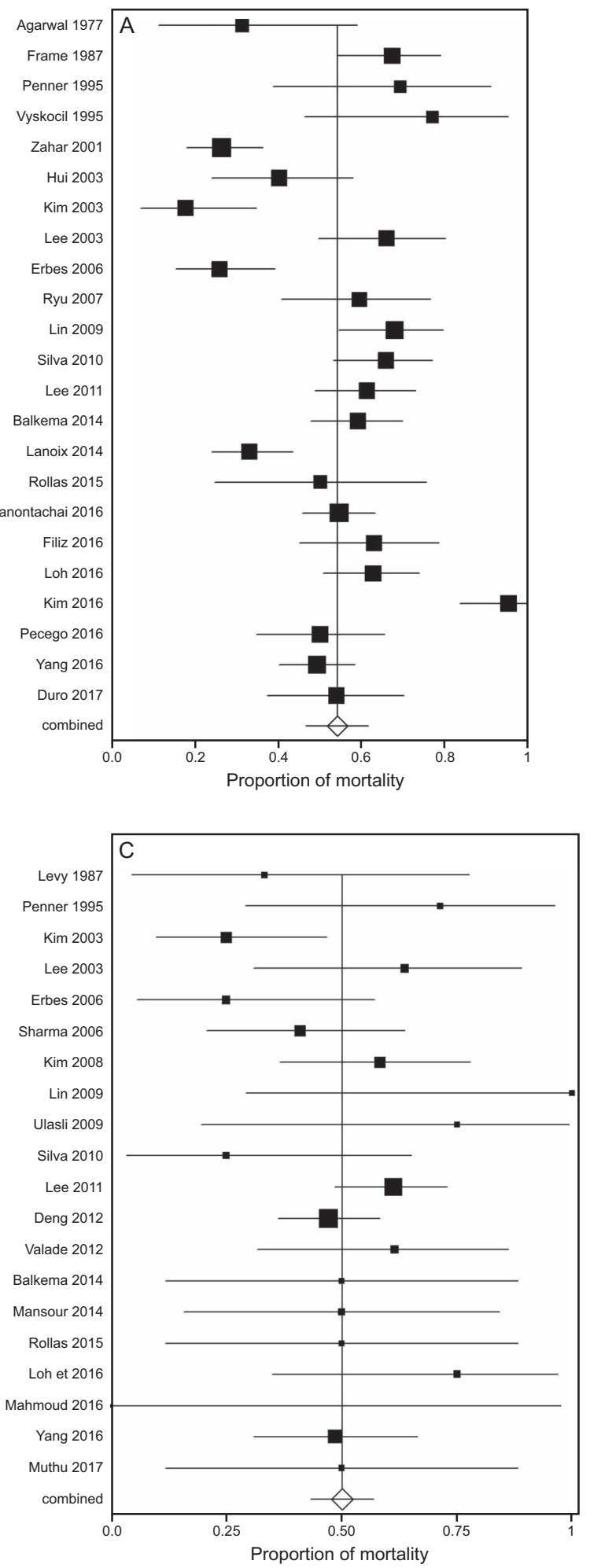
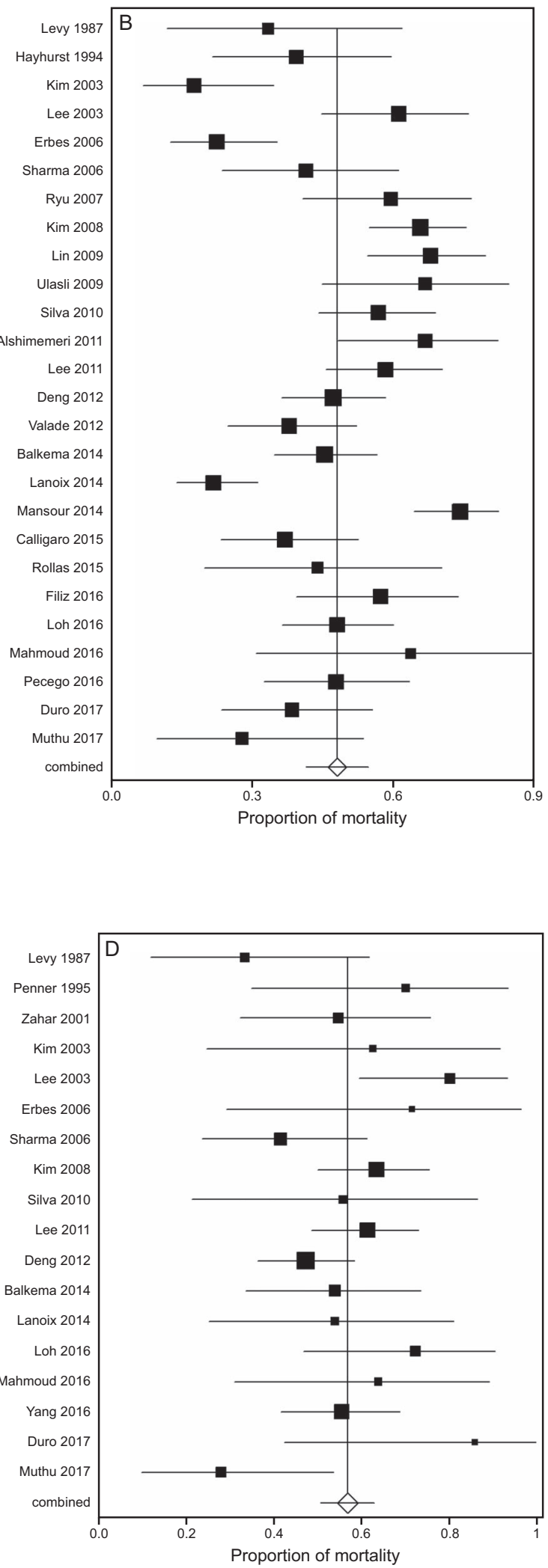

Fig. 2. Forest plots depicting hospital mortality (A), ICU mortality (B), mortality in miliary tuberculosis (C), and mortality in subjects with tuberculosis-related ARDS (D), among subjects with tuberculosis who required ICU admission. The proportion of mortality in individual studies is represented by a square through which runs a horizontal line $(95 \% \mathrm{Cl})$. Pooled mortality is represented by the diamond and the $95 \% \mathrm{Cl}$ is represented by the line running through it. 


\section{TUBERCULOSIS IN THE ICU}

\begin{tabular}{llcc} 
A Studies & \multicolumn{1}{c}{ Estimate $(95 \% \mathrm{CI})$} & Miliary & Non-miliary \\
& & & \\
Levy 1987 & $1.000(0.11-8.95)$ & $2 / 6$ & $3 / 9$ \\
Kim 2003 & $7.378(0.38-144.46)$ & $6 / 24$ & $0 / 10$ \\
Lee 2003 & $1.167(0.28-4.87)$ & $7 / 11$ & $18 / 30$ \\
Erbes 2006 & $1.200(0.27-5.28)$ & $3 / 12$ & $10 / 46$ \\
Sharma 2006 & $0.923(0.16-5.16)$ & $9 / 22$ & $3 / 7$ \\
Kim 2008 & $0.653(0.25-1.71)$ & $14 / 24$ & $45 / 66$ \\
Lin 2009 & $3.640(0.18-74.09)$ & $3 / 3$ & $37 / 56$ \\
Ulasli 2009 & $1.615(0.14-18.58)$ & $3 / 4$ & $13 / 20$ \\
Silva 2010 & $0.213(0.04-1.15)$ & $2 / 8$ & $36 / 59$ \\
Valade 2012 & $3.733(1.01-13.78)$ & $8 / 13$ & $12 / 40$ \\
Balkema 2014 & $1.222(0.23-6.43)$ & $3 / 6$ & $36 / 80$ \\
Mansour 2014 & $0.314(0.07-1.36)$ & $4 / 8$ & $70 / 92$ \\
Rollas 2015 & $1.500(0.19-11.54)$ & $3 / 6$ & $4 / 10$ \\
Loh 2016 & $3.700(0.70-19.69)$ & $6 / 8$ & $30 / 67$ \\
Mahmoud 2016 & $0.156(0.00-4.86)$ & $0 / 1$ & $7 / 10$ \\
Muthu 2017 & $5.000(0.55-45.40)$ & $3 / 6$ & $2 / 12$ \\
& & & \\
Overall $\left(I^{2}=18.74 \%, P=.24\right)$ & $1.154(0.711-1.874)$ & $76 / 162$ & $326 / 614$
\end{tabular}

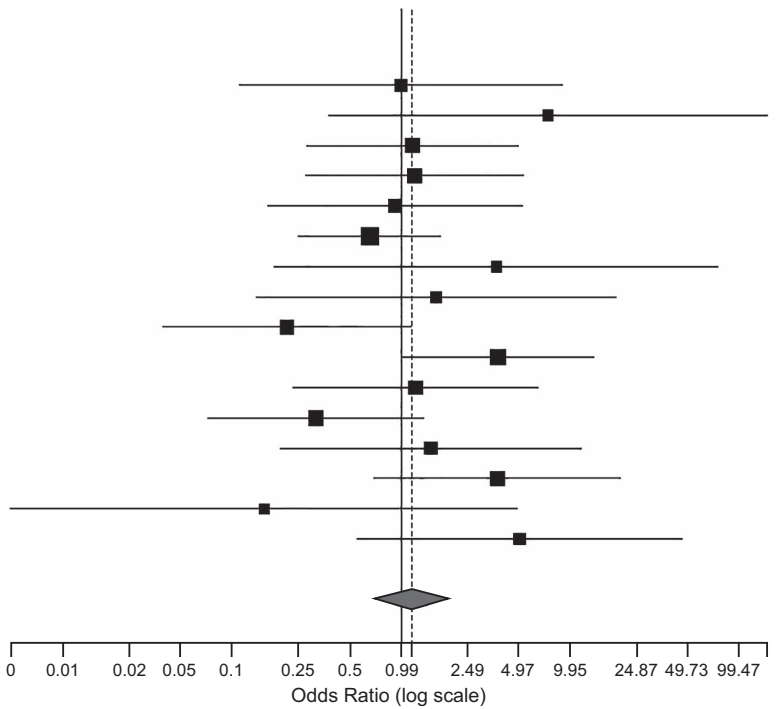

B

Studies

Estimate (95\% Cl)

TB-ARDS Non-ARDS-TB

Kim 2003

Lee 2003

Erbes 2006

Kim 2008

Silva 2010

Balkema 2014

Lanoix 2014

Loh 2016

Duro 2017

41.667 (3.56-486.94)

$8.800(2.08-37.20)$

$13.438(2.21-81.71)$

$0.740(0.29-1.90)$

$0.947(0.23-3.89)$

$1.633(0.65-4.12)$

$5.833(1.70-20.00)$

$3.843(1.21-12.25)$

15.333 (1.61-145.90)

Overall $\left(I^{2}=68.03 \%, P=.002\right)$

$3.881(1.727-8.721)$

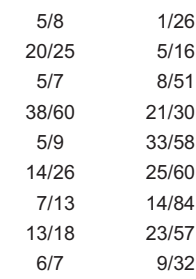

$113 / 173 \quad 139 / 414$

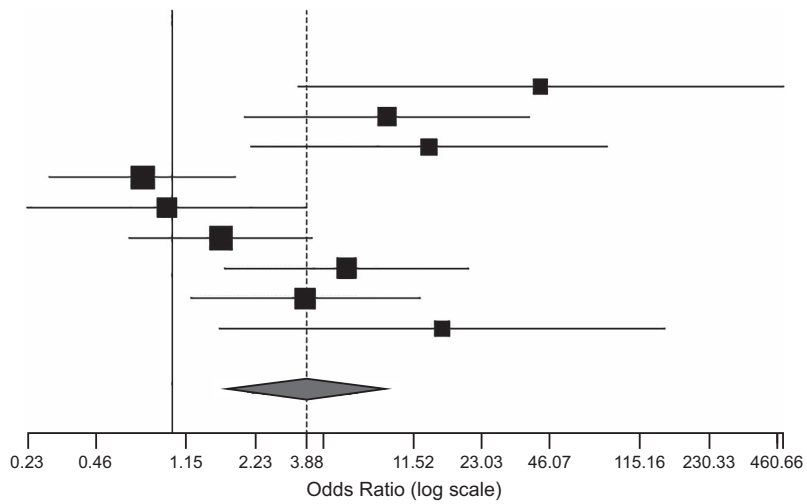

Fig. 3. Forest plots, depicting the comparison of mortality in subjects who were critically ill with or without miliary tuberculosis (A) and tuberculosis with or without ARDS (B). The odds ratio of mortality in individual studies is represented by a square through which runs a horizontal line $(95 \% \mathrm{Cl})$. Pooled odds ratio is represented by the diamonds.

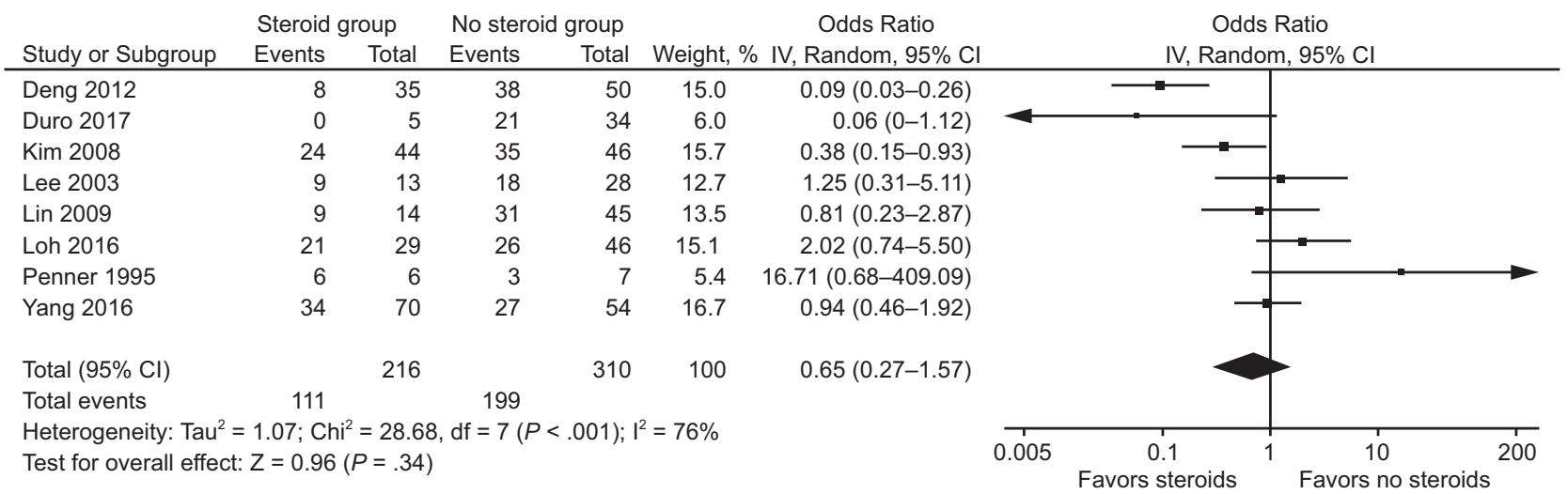

Fig. 4. Forest plot, depicting the mortality in subjects with tuberculosis who were critically ill with or without the use of systemic glucocorticoids. The odds ratio of mortality in individual studies is represented by a square through which runs a horizontal line $(95 \% \mathrm{Cl})$. The diamond represents the pooled odds ratio. 


\section{TUBerCULOSIS IN THE ICU}

infections. ${ }^{39,46}$ Development of nosocomial infection was associated with increased mortality in some studies. ${ }^{2,28}$

Tuberculosis is an unusual cause of ARDS and is believed to result from inflammation mounted against mycobacterial cell wall components, similar to bacterial sepsis. ${ }^{47}$ The pooled analysis in the current study indicated that the occurrence of ARDS in tuberculosis was associated with higher odds of mortality compared with subjects with tuberculosis but without ARDS. However, tuberculosis-related ARDS behaves like ARDS due to any other etiology. ${ }^{9,48}$ In a recent study, no difference was observed in outcomes between subjects with tuberculosis-related ARDS and ARDS due to other causes. ${ }^{7}$ Miliary tuberculosis is considered to be associated with high mortality because it signifies mycobacteremia. However, we found the survival to be similar in subjects with or without miliary tuberculosis.

In a recent meta-analysis, the use of glucocorticoids was found to reduce mortality in all forms of tuberculosis, including pulmonary tuberculosis. ${ }^{10}$ However, the analysis predominantly included subjects with meningitis and not specifically subjects who were critically ill. ${ }^{10}$ Contrary to the previous study, our study did not find any survival benefit with the use of systemic glucocorticoids. The lack of benefit with glucocorticoids could be due to the variable dose and duration in these studies. ${ }^{5,43}$ Also, patients who are critically ill and are treated with glucocorticoids represent an even sicker group of individuals and leads to a selection bias. Thus, the role of systemic glucocorticoids in individuals who are critically ill remains unclear and needs further evaluation in prospective studies.

Our review had a few limitations. Most studies included in the review had a retrospective study design with a limited number of subjects. However, a prospective study seemed impractical due to the low frequency of patients with tuberculosis being admitted to the ICU. The results of this meta-analysis could not be extrapolated to patients with human immunodeficiency virus infection, meningeal tuberculosis, and drug-resistant tuberculosis because separate information was not available for such individuals. In one study that exclusively involved subjects with tuberculosis and human immunodeficiency virus who were critically ill, the ICU mortality (52\%) was similar to the pooled mortality observed in the current analysis although the time to death was shorter in subjects with lower CD4 counts. ${ }^{42}$ The odds for ARDS and miliary tuberculosis mortality were calculated by using the numbers of cases and controls reported. Therefore, "crude" odds ratio of death was provided in this review and may not represent the true burden of ARDS and miliary tuberculosis on death. There also was significant heterogeneity in the criteria used to define tuberculosis and the regimen of anti-tuberculosis therapy used. Also, most of the studies were of short duration and did not report on the long-term out- comes. Finally, the role of glucocorticoids in subjects with tuberculosis-related ARDS and miliary tuberculosis could not be ascertained because the individual studies did not provide this information.

\section{Conclusions}

Tuberculosis is an uncommon cause of ICU admission, with a high ICU mortality. The role of systemic glucocorticoids in patients with tuberculosis who are critically ill remains unclear and needs further evaluation.

\section{REFERENCES}

1. Penner C, Roberts D, Kunimoto D, Manfreda J, Long R. Tuberculosis as a primary cause of respiratory failure requiring mechanical ventilation. Am J Respir Crit Care Med 1995;151(3 Pt 1):867-872.

2. Silva DR, Menegotto DM, Schulz LF, Gazzana MB, Dalcin PT. Mortality among patients with tuberculosis requiring intensive care: a retrospective cohort study. BMC Infect Dis 2010;10:54.

3. Balkema CA, Irusen EM, Taljaard JJ, Koegelenberg CF. Tuberculosis in the intensive care unit: a prospective observational study. Int J Tuberc Lung Dis 2014;18(7):824-830.

4. Bastos HN, Osório NS, Castro AG, Ramos A, Carvalho T, Meira L, et al. A Prediction Rule to Stratify Mortality Risk of Patients with Pulmonary Tuberculosis. PLoS One 2016;11(9):e0162797.

5. Deng W, Yu M, Ma H, Hu LA, Chen G, Wang Y, et al. Predictors and outcome of patients with acute respiratory distress syndrome caused by miliary tuberculosis: a retrospective study in Chongqing, China. BMC Infect Dis 2012;12:121.

6. Sharma SK, Mohan A, Banga A, Saha PK, Guntupalli KK. Predictors of development and outcome in patients with acute respiratory distress syndrome due to tuberculosis. Int J Tuberc Lung Dis 2006; 10(4):429-435.

7. Muthu V, Dhooria S, Aggarwal AN, Behera D, Sehgal IS, Agarwal R. Acute Respiratory Distress Syndrome Due To Tuberculosis in a Respiratory ICU Over a 16-Year Period. Crit Care Med 2017;45(10): e1087-e1090.

8. World Health Organization. Global tuberculosis report 2016. Geneva: WHO; 2015. http://apps.who.int/iris/bitstream/10665/250441/ 1/9789241565394_eng.pdf. Accessed March 31, 2017.

9. Agarwal R, Gupta D, Aggarwal AN, Behera D, Jindal SK. Experience with ARDS caused by tuberculosis in a respiratory intensive care unit. Intensive Care Med 2005;31(9):1284-1287.

10. Critchley JA, Young F, Orton L, Garner P. Corticosteroids for prevention of mortality in people with tuberculosis: a systematic review and meta-analysis. Lancet Infect Dis 2013;13(3):223-237.

11. Liberati A, Altman DG, Tetzlaff J, Mulrow C, Gøtzsche PC, Ioannidis JP, et al. The PRISMA statement for reporting systematic reviews and meta-analyses of studies that evaluate health care interventions: explanation and elaboration. Ann Intern Med 2009;151(4): W65-W94.

12. Kmet LM, Lee RC, LS C. Standard quality assessment criteria for evaluating primary research papers from a variety of fields. 2004. Edmonton: Alberta Heritage foundation for medical research. www.ahfmr.ab.ca. Accessed February 14, 2018.

13. Deeks. JJ, Higgins. JPT, Altman. DG. Analysing and presenting results. In: Alderson P, Green S, Higgins JPT, editors. Cochrane reviewers' handbook 422 [updated Mar 2004]. Chichester, UK: John Wiley \& Son; 2004;68-139. 


\section{TUBERCULOSIS IN THE ICU}

14. Egger M, Davey Smith G, Schneider M, Minder C. Bias in metaanalysis detected by a simple, graphical test. BMJ 1997;315(7109): 629-634.

15. Begg CB, Mazumdar M. Operating characteristics of a rank correlation test for publication bias. Biometrics 1994;50(4):1088-1101.

16. Agarwal MK, Muthuswamy PP, Banner AS, Shah RS, Addington WW. Respiratory failure in pulmonary tuberculosis. Chest 1977; 72(5):605-609.

17. Frame RN, Johnson MC, Eichenhorn MS, Bower GC, Popovich J, Jr. Active tuberculosis in the medical intensive care unit: a 15-year retrospective analysis. Crit Care Med 1987;15(11):1012-1014.

18. Levy H, Kallenbach JM, Feldman C, Thorburn JR, Abramowitz JA. Acute respiratory failure in active tuberculosis. Crit Care Med 1987; 15(3):221-225.

19. Hayhurst DM, Kussman BD, Potgeiter PD. Acute Respiratory Failure due to Pulmonary Tuberculosis - A Five Year Analysis in an Intensive Care Unit. S Afr J Crit Care 1994;10(1):4-7.

20. Vyskocil JJ, Marik P, Greville HW. Survival with tuberculosis pneumonia necessitating mechanical ventilation. Clin Pulm Med 1995; 2(3):152-156

21. Zahar JR, Azoulay E, Klement E, De Lassence A, Lucet JC, Regnier B, et al. Delayed treatment contributes to mortality in ICU patients with severe active pulmonary tuberculosis and acute respiratory failure. Intensive Care Med 2001;27(3):513-520.

22. Hui C, Wu CL, Chan MC, Kuo IT, Chiang CD. Features of severe pneumonia in patients with undiagnosed pulmonary tuberculosis in an intensive care unit. J Formos Med Assoc 2003;102(8):563-569.

23. Kim JY, Park YB, Kim YS, Kang SB, Shin JW, Park IW, et al. Miliary tuberculosis and acute respiratory distress syndrome. Int $\mathbf{J}$ Tuberc Lung Dis 2003;7(4):359-364.

24. Lee PL, Jerng JS, Chang YL, Chen CF, Hsueh PR, Yu CJ, et al. Patient mortality of active pulmonary tuberculosis requiring mechanical ventilation. Eur Respir J 2003;22(1):141-147.

25. Erbes R, Oettel K, Raffenberg M, Mauch H, Schmidt-Ioanas M, Lode $\mathrm{H}$. Characteristics and outcome of patients with active pulmonary tuberculosis requiring intensive care. Eur Respir J 2006;27(6): 1223-1228.

26. Ryu YJ, Koh WJ, Kang EH, Suh GY, Chung MP, Kim H, et al. Prognostic factors in pulmonary tuberculosis requiring mechanical ventilation for acute respiratory failure. Respirology 2007;12(3):406411.

27. Kim YJ, Pack KM, Jeong E, Na JO, Oh YM, Lee SD, et al. Pulmonary tuberculosis with acute respiratory failure. Eur Respir J 2008; 32(6): $1625-1630$.

28. Lin SM, Wang TY, Liu WT, Chang CC, Lin HC, Liu CY, et al. Predictive factors for mortality among non-HIV-infected patients with pulmonary tuberculosis and respiratory failure. Int $\mathrm{J}$ Tuberc Lung Dis 2009;13(3):335-340.

29. Ulasli SS, Ulubay G, Arslan NG, Sezer S, Akcay S, Eyuboglu FO, et al. Characteristics and outcomes of end-stage renal disease patients with active tuberculosis followed in intensive care units. Saudi J Kidney Dis Transpl 2009;20(2):254-259.

30. Alshimemeri AA, Arabi YM, Al-Jahdali H, Olayan A, Al Harbi O, Memish Z. Clinical presentation and outcome of patients diagnosed with active pulmonary tuberculosis in a large critical care unit. Crit Care Shock 2011;14(1):1-6.

31. Lee K, Kim JH, Lee JH, Lee WY, Park MS, Kim JY, et al. Acute respiratory distress syndrome caused by miliary tuberculosis: a multicentre survey in South Korea. Int J Tuberc Lung Dis 2011;15(8): 1099-1103.

32. Valade S, Raskine L, Aout M, Malissin I, Brun P, Deye N, et al. Tuberculosis in the intensive care unit: A retrospective descriptive cohort study with determination of a predictive fatality score. Can J Infect Dis Med Microbiol 2012;23(4):173-178.

33. Lanoix JP, Gaudry S, Flicoteaux R, Ruimy R, Wolff M. Tuberculosis in the intensive care unit: a descriptive analysis in a low-burden country. Int J Tuberc Lung Dis 2014;18(5):581-587.

34. Mansour M, Madkour A, Fouda M. Outcome of active pulmonary tuberculosis patients requiring respiratory intensive care admission. Egypt J Bronchol 2014;8(2):79-86.

35. Calligaro GL, Theron G, Khalfey H, Peter J, Meldau R, Matinyenya $\mathrm{B}$, et al. Burden of tuberculosis in intensive care units in Cape Town, South Africa, and assessment of the accuracy and effect on patient outcomes of the Xpert MTB/RIF test on tracheal aspirate samples for diagnosis of pulmonary tuberculosis: a prospective burden of disease study with a nested randomised controlled trial. Lancet Respir Med 2015;3(8):621-630

36. Rollas K, Kara A, Ortac Ersoy NE, Ozmen Suner K, Gullu MN, Ocal $\mathrm{S}$, et al. Acute tuberculosis in the intensive care unit. Turk J Med Sci 2015;45(4):882-887.

37. Bhurayanontachai R, Maneenil K. Factors influencing development and mortality of acute respiratory failure in hospitalized patient with active pulmonary tuberculosis: a 10-year retrospective review. J Thorac Dis 2016;8(7):1721-1730.

38. Filiz KA, Levent D, Emel E, Pelin U, Turkay A, Aybuke K. Characteristics of Active Tuberculosis Patients Requiring Intensive Care Monitoring and Factors Affecting Mortality. Tuberc Respir Dis (Seoul) 2016;79(3):158-164.

39. Kim S, Kim H, Kim WJ, Lee SJ, Hong Y, Lee HY, et al. Mortality and predictors in pulmonary tuberculosis with respiratory failure requiring mechanical ventilation. Int J Tuberc Lung Dis 2016;20(4): 524-529.

40. Loh WJ, Yu Y, Loo CM, Low SY. Factors associated with mortality among patients with active pulmonary tuberculosis requiring intensive care. Singapore Med J 2017;58(11):656-659.

41. Mahmoud ES, Baharoon SA, Alsafi E, Al-Jahdaly H. Acute respiratory distress syndrome complicating community-acquired pneumonia secondary to mycobacterium tuberculosis in a tertiary care center in Saudi Arabia. Saudi Med J 2016;37(9):973-978.

42. Pecego AC, Amancio RT, Ribeiro C, Mesquita EC, Medeiros DM, Cerbino J, et al. Six-month survival of critically ill patients with HIV-related disease and tuberculosis: a retrospective study. BMC Infect Dis 2016;16:270.

43. Yang JY, Han M, Koh Y, Kim WS, Song JW, Oh YM, et al. Effects of Corticosteroids on Critically Ill Pulmonary Tuberculosis Patients With Acute Respiratory Failure: A Propensity Analysis of Mortality. Clin Infect Dis 2016;63(11):1449-1455.

44. Duro RP, Figueiredo Dias P, Ferreira AA, Xerinda SM, Lima Alves C, Sarmento AC, et al. Severe Tuberculosis Requiring Intensive Care: A Descriptive Analysis. Crit Care Res Pract 2017;2017: 9535463.

45. Cookson ST, Jarvis WR. Prevention of nosocomial transmission of Mycobacterium tuberculosis. Infect Dis Clin North Am 1997;11(2): 385-409.

46. Wang CS, Chen HC, Yang CJ, Wang WY, Chong IW, Hwang JJ, et al. The impact of age on the demographic, clinical, radiographic characteristics and treatment outcomes of pulmonary tuberculosis patients in Taiwan. Infection 2008;36(4):335-340.

47. Shinnick TM, King CH, Quinn FD. Molecular biology, virulence, and pathogenicity of mycobacteria. Am J Med Sci 1995;309(2): 92-98.

48. Agarwal R, Gupta D, Handa A, Aggarwal AN. Noninvasive ventilation in ARDS caused by Mycobacterium tuberculosis: report of three cases and review of literature. Intensive Care Med 2005;31(12): $1723-1724$. 